\title{
Evaluasi Suhu dan Kelembapan Ruang Pengolahan dan Ruang Distribusi Instalasi Gizi di RSUD Kabupaten Sidoarjo
}

\section{Temperature and Humidity Evaluation in Processing Room and Distribution Room at the Nutrition Installation of Sidoarjo Regency Hospital}

\author{
Yulianti Wulan Sari ${ }^{1}$, Melania Rahadiyanti ${ }^{2}$, Dominikus Raditya Atmaka*1
}

\begin{abstract}
ABSTRAK
Latar Belakang: Suhu dan kelembapan dalam ruang pengolahan dan distribusi merupakan hal penting yang harus diperhatikan. Suhu dan kelembapan ruangan yang baik akan menjaga makanan agar terhindar dari aktivitas mikroorganisme. Suhu dan kelembapan juga menjadi hal penting bagi penjamah makanan agar tetap merasa aman dan nyaman pada saat bekerja.

Tujuan: Penelitian ini bertujuan untuk melihat gambaran suhu dan kelembapan udara pada ruangan pengolahan dan distribusi di Instalasi Gizi RSUD Kabupaten Sidoarjo.

Metode: Penelitian ini menggunakan desain retrospektif. Pengambilan data dilakukan sebanyak 4 kali sehari yaitu pagi ( sekitar pukul 10.00), siang (sekitar pukul 14.00) sore (sekitar pukul 17.00), dan malam (sekitar pukul 19.00). Penelitian suhu dan kelembapan dilakukan di ruang pengolahan dan distribusi. Pengumpulan data dilakukan dengan cara melihat laporan penilaian ketepatan suhu dan kelembapan pada bulan april, mei, juli dan agustus tahun 2019. Suhu standar yang digunakan adalah $22-30^{\circ} \mathrm{C}$, sedangkan kelembapannya sekitar $40-60 \%$. digunakan .

Hasil: Suhu di ruang pengolahan dan ruang distribusi lebih tinggi dibandingkan dengan standar rumah sakit yakni antara 25$27^{\circ} \mathrm{C}$. Akan tetapi, apabila dibandingkan dengan standar Permenkes, suhu masih tergolong aman. Kelembapan udara di ruang pengolahan masih berada dalam standar, namun di ruang distribusi kelembapan udara lebih tinggi dari standar rumah sakit dan permenkes, yakni $40-70 \%$.

Kesimpulan: Gambaran Suhu dan kelembapan udara di ruangan pengolahan dan distribusi di Instalasi Gizi RSUD Kabupaten Sidoarjo terdapat data yang cukup fluktuatif. Secara umum, suhu dan kelembapan udara di ruang pengolahan dan distribusi sudah memenuhi standar yang ditetapkan oleh Kementerian Kesehatan dalam Permenkes no 7 Tahun 2019.
\end{abstract}

Kata kunci: Suhu, Kelembapan, Ruang Pengolahan, Ruang Distribusi

\section{ABSTRACT}

Background: Temperature and humidity in the processing and distribution room are important things to consider. Good room temperature and humidity will keep food from avoiding microorganism activity. Temperature and humidity are also important for waiters and waiters to feel safe and comfortable at work.

Objectives: This study aim to look at the description of temperature and humidity in the processing and distribution room at the Nutrition Installation of Sidoarjo Regency Hospital.

Methods: This research used cohort retrospective design. Data collection were taken 4 times a day, that is in the morning (around 10:00), afternoon (around 14:00) evening (around 17:00), and night (around 19:00). Temperature and humidity research were carried out in the processing and distribution room. Data collection were done by looking at the accuracy humidity and temperature assessment report in April, May, July and August 2019. The standard temperature used is 22-30 $C$, while the humidity is around $40-60 \%$.

Results: Temperature in processing and distribution room were higher than hospital standard, which is between $25-27^{\circ} \mathrm{C}$. But if compared with Ministry of Health Rule, the temperature were still safe. Air humidity in processing room were still on the standard, but air humidity in distribution room were higher than hospital standard and Ministry of Health Rule, that is 40$70 \%$.

Conclusions: The temperature and humidity in the processing and distribution room in the Nutrition Installation of the Sidoarjo Regency Hospital, there are quite fluctuating data. In general, the temperature and humidity in the processing and distribution rooms have met the standards set by the Ministry of Health in Permenkes No.72019.

Keywords: Temperature, Humidity, Processing Room, Distribution Room 


\author{
*Korespondensi: \\ dominikus.raditya@fkm.unair.ac.id \\ Dominikus Raditya Atmaka \\ ${ }^{1}$ Departemen Gizi Kesehatan, Fakultas Kesehatan Masyarakat, Universitas Airlangga, Jl. Mulyorejo Kampus C, Surabaya 60115, \\ Indonesia \\ 2Interior Architecture Department, Universitas Ciputra, Citraland CBD Boulevard, Surabaya, Indonesia
}

\section{PENDAHULUAN}

Makanan merupakan salah satu unsur penting bagi pasien di rumah sakit. Bagi pasien, makanan menjadi sumber energi sehingga dapat meringankan tanda gejala yang dialami pasien dan mempercepat proses penyembuhan serta pemulihan pasien. ${ }^{1}$ Studi yang telah dilakukan di Indonesia pada beberapa rumah sakit di Jakarta menunjukkan sebanyak $20-60 \%$ pasien malnutrisi dan $69 \%$ mengalami penurunan status gizi selama rawat inap di rumah sakit. ${ }^{2}$ Kejadian malnutrisi yang terjadi pada anak juga seringkali ditemui di Rumah Sakit. Studi yang dilakukan oleh Koen dan Jessie di Rumah Sakit Rotterdam menunjukkan sebanyak $6,1-40,9 \%$ pasien anak-anak mengalami malnutrisi saat masuk Rumah Sakit ${ }^{3}$. Asupan makan pasien di rumah sakit tergantung pada tingkat kenyamanan pasien dalam mendapatkan makanan, mulai dari bentuk makanan, penyajian makanan, variasi makanan dan penampilan makanan. Penyajian makanan dengan pengaturan suhu pada waktu penyajian memegang peran penting dalam menentukan cita rasa makanan. Penyelenggaraan makanan dengan skala besar, memerlukan ketelitian dalam pendistribusian makanan terutama suhu makanan, seperti suhu pada nasi, lauk hewani dan lauk nabati. Konsumen cenderung kurang memiliki selera makan bila mengonsumsi makanan dengan suhu rendah atau tidak hangat. ${ }^{4}$

Suhu dapat menunjukkan suatu keadaan panas atau dingin. Hidangan makanan dalam keadaan panas dapat menimbulkan aroma yang mampu menjadi daya tarik makanan untuk dikonsumsi. ${ }^{5}$ Dalam proses pengolahan dan penyajian makanan, suhu dan kelembapan di ruang pengolahan dan distribusi menjadi faktor penting agar makanan dapat sampai kepada pasien dalam kondisi bersih dan suhu yang memadai. ${ }^{1}$ Mutu pelayanan penyelenggaraan makanan rumah sakit dapat dilihat melalui respon pasien sebagai subjek yang mendapatkan pelayanan berupa makanan di ruang rawat inap. Persentase ketidakpuasan pasien setidaknya $<10 \%$ dari seluruh hasil survei. ${ }^{6}$

Ruang produksi dan distribusi sangat penting untuk menjaga hygiene makanan sehingga dapat meningkatkan asupan gizi pasien selain itu juga bertujuan untuk melindungi penjamah makanan yang bertugas dalam proses produksi dan distribusi. ${ }^{11}$ Ruang pengolahan makanan harus memiliki ventilasi yang cukup agar sinar matahari dapat masuk dan menerangi ruang pengolahan. Ruang pengolahan menghasilkan banyak uap panas yang menyebabkan suhu ruangan meningkat. Peningkatan suhu dan uap panas akan meningkatkan jumlah karbon dioksida dan menyebabkan ruangan menjadi lembab. ${ }^{12,13}$ Ventilasi yang cukup akan membantu mengurangi kelembapan dan membuang sisa uap panas yang dihasilkan pada saat pengolahan. Untuk memaksimalkan pembuangan panas akibat hasil pengolahan, pada atas kompor dapat dilengkapi dengan alat pembuang asap atau ventilator agar uap hasil pengolahan dapat secara langsung keluar. ${ }^{14}$

Ruang pengolahan dan distribusi agar dapat digunakan oleh pekerja dengan nyaman, harus memiliki suhu dan kelembapan standar sehingga dapat menghasilkan makanan dalam kondisi bersih dan suhu yang memadai, yakni berkisar antara $22-30^{\circ} \mathrm{C}$ dan kadar kelembapan berkisar antara $40-60 \% .{ }^{15}$ Apabila ruang pengolahan yang sudah dilengkapi dengan ventilasi yang cukup dan alat pembuang asap tetapi suhu dalam ruang pengolahan masih dirasa cukup panas akibat proses produksi, maka dapat ditambahkan dengan pendingin ruangan untuk membantu menurunkan suhu dan kelembapan agar sesuai standar. ${ }^{16}$

RSUD Kabupaten Sidoarjo merupakan salah satu rumah sakit yang mengelola sendiri makanan pasien dalam jumlah besar. Setiap harinya, ada sekitar 600-700 pasien yang harus dipenuhi kebutuhan gizinya. Saat ini belum ada publikasi mengenai gambaran suhu dan kelembapan ruang distribusi dan ruang pengolahan di RSUD Kabupaten Sidoarjo. Oleh karena itu, berdasarkan pemaparan diatas peneliti ingin mengetahui gambaran suhu dan kelembapan ruang pengolahan dan ruang distribusi di RSUD Sidoarjo terkait dengan mutu pelayanan gizi rumah sakit.

\section{METODE}

Penelitian ini menggunakan metode deskriptif analitik dengan desain penelitian retrospektif. Penelitian bertujuan untuk melihat gambaran suhu dan kelembapan ruang pengolahan dan distribusi pada instalasi gizi RSUD Kabupaten Sidoarjo. Penelitian dilaksanakan di RSUD Kabupaten Sidoarjo pada September 2019. Penelitian suhu dan kelembapan dilakukan di ruang pengolahan dan distribusi. Alat ukur yang digunakan adalah termometer suhu ruangan htc-1/thermometer hygrometer htc 1 digital (Thermometer dan Hygrometer Indoor). dengan merk OneMed Alat ukur ini menampilkan suhu, kelembaban dan waktu dalam satu layar (Display temperature, humidity and time simultaneously). Ukuran temperatur dalam satuan derajat celcius $\left({ }^{\circ} \mathrm{C}\right)$ dengan kemampuan mendeteksi suhu mulai dari $-10 \mathrm{C} \mathrm{s} / \mathrm{d} 50 \mathrm{C}$, dan resolusi $0.1^{\circ} \mathrm{C}$. Ukuran kelembaban dalam satuan kelembapan relative (RH) dengan kemampuan mendeteksi $10 \%$ s/d $99 \%$, dan resolusi $1 \%$. Ukuran waktu dalam satuan jam dan menit dengan format 24 jam atau 12 jam (AM/PM).

Pengambilan data menggunakan teknik observasi dan dokumentasi dengan melihat laporan penilaian ketepatan suhu dan kelembabapan di ruang 
pengolahan dan distribusi yang diamati langsung oleh ahli gizi ruang pengolahan dan distribusi yang bertugas setiap harinya dengan pengambilan di dua titik yakni di ruang pengolahan dan ruang distribusi. Kondisi lingkungan di sekitar ruangan pengolahan tertutup dengan 2 ventilasi yang tidak terbuka dan tertutup kaca dengan 6 buah lampu yang menyala, Kondisi lingkungan di sekitar ruangan distribusi tertutup dengan 4 ventilasi yang sering terbuka untuk penyaluran makanan pasien ke troli dengan 4 buah lampu yang menyala. Pengumpulan data dilakukan dengan cara melihat laporan suhu dan kelembapan pada bulan april, mei, juli dan agustus 2019 yang telah diobservasi sebanyak 4 kali sehari yaitu pagi ( sekitar pukul 10.00), siang (sekitar pukul 14.00) sore (sekitar pukul 17.00), dan malam (sekitar pukul 19.00). Suhu dan kelembapan yang ada pada ruangan tersebut haruslah masuk ke dalam kategori nyaman. Berdasarkan Permenkes tahun 2019, dapur rumah sakit hendaknya didesain sedemikian rupa agar dapat menyediakan suhu dan kelembapan standar. Suhu standar berdasarkan Permenkes tahun 2019 adalah $22-30^{\circ} \mathrm{C}$, sedangkan kelembapannya sekitar $40-60 \%$ dan berdasarkan RSUD Sidoarjo suhu standarnya adalah $25-27^{\circ} \mathrm{C}$ sedangkan kelembapannya $40-70 \%$

\section{HASIL DAN PEMBAHASAN}

Kualitas udara yang terdapat pada ruang pengolahan maupun distribusi mempengaruhi pekerja dalam melakukan aktivitasnya. ${ }^{15}$ RSUD Sidoarjo memiliki standar tersendiri mengenai suhu dan kelembapan. Suhu standar ruang pengolahan dan distribusi RSUD Sidoarjo adalah $25-27^{\circ} \mathrm{C}$, sedangkan kelembapan standar untuk kedua ruang tersebut adalah $40-70 \%$. Perbedaan standar dapat mempengaruhi interpretasi data pengamatan. Dalam penelitian ini, pengamatan suhu dan kelembapan dilakukan di ruang pengolahan dan distribusi.
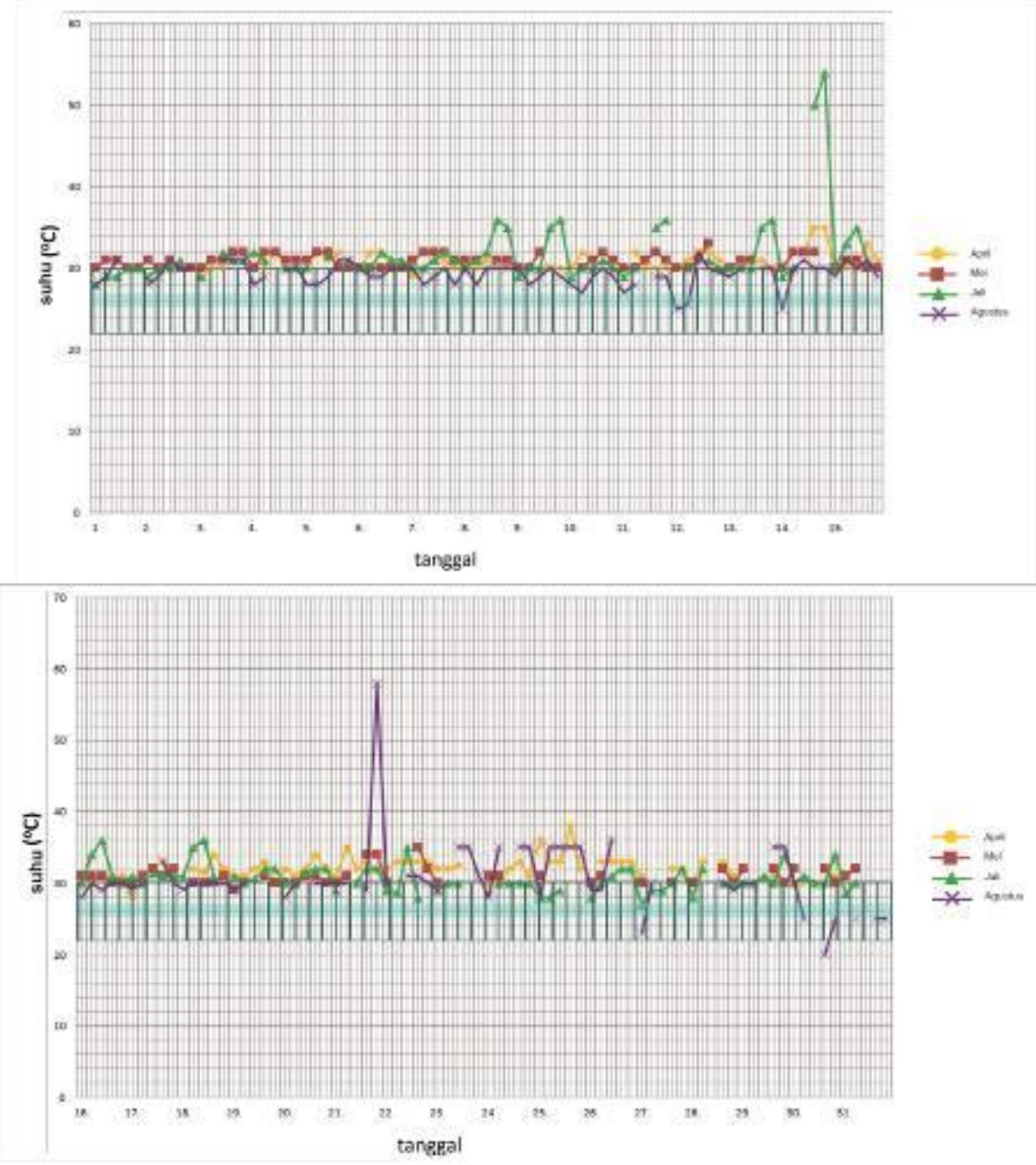

Gambar 1. Suhu ruang pengolahan

Ket :

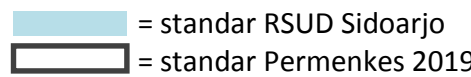

Berdasarkan Gambar 1 dapat dilihat bahwa data suhu hasil pengamatan petugas selama 4 bulan di ruang pengolahan lebih tinggi dibandingkan dengan standar rumah sakit. Akan tetapi, apabila dibandingkan dengan standar Permenkes, sebagian data masih tergolong pada suhu yang aman. Ruang pengolahan cenderung memiliki 
suhu yang lebih tinggi karena adanya aktivitas pengolahan dengan suhu tinggi, sehingga mempengaruhi suhu ruangan. Paparan panas yang berlebihan dari lingkungan kerja dapat menimbulkan masalah kesehatan dan fungsi kognitif yang apabila tidak dilakukan perbaikan dapat berakibat pada keselamatan kerja. ${ }^{17}$ Oleh karena itu diperlukan evaluasi mengenai sistem penghawaan di ruang pengolahan. Penelitian Reglier-Poupet (2005) di Necker Enfants Malades Hospital menunjukkan hasil yang hampir sama dimana terdapat fluktuasi suhu di dapur rumah sakit antara $17^{\circ} \mathrm{C}$ sampai $23^{\circ} \mathrm{C}$. Fluktuasi suhu pada ruang dapur dapat mempengaruhi suhu internal dari makanan yang dihasilkan dan memungkinkan menjadi media yang baik untuk pertumbuhan bakteri. ${ }^{19}$ Oleh karena itu diperlukan evaluasi mengenai sistem penghawaan di ruang pengolahan berdasarkan hasil pengukuran suhu secara berkala untuk mengetahui apakah diperlukan modifikasi aliran udara atau ventilasi.
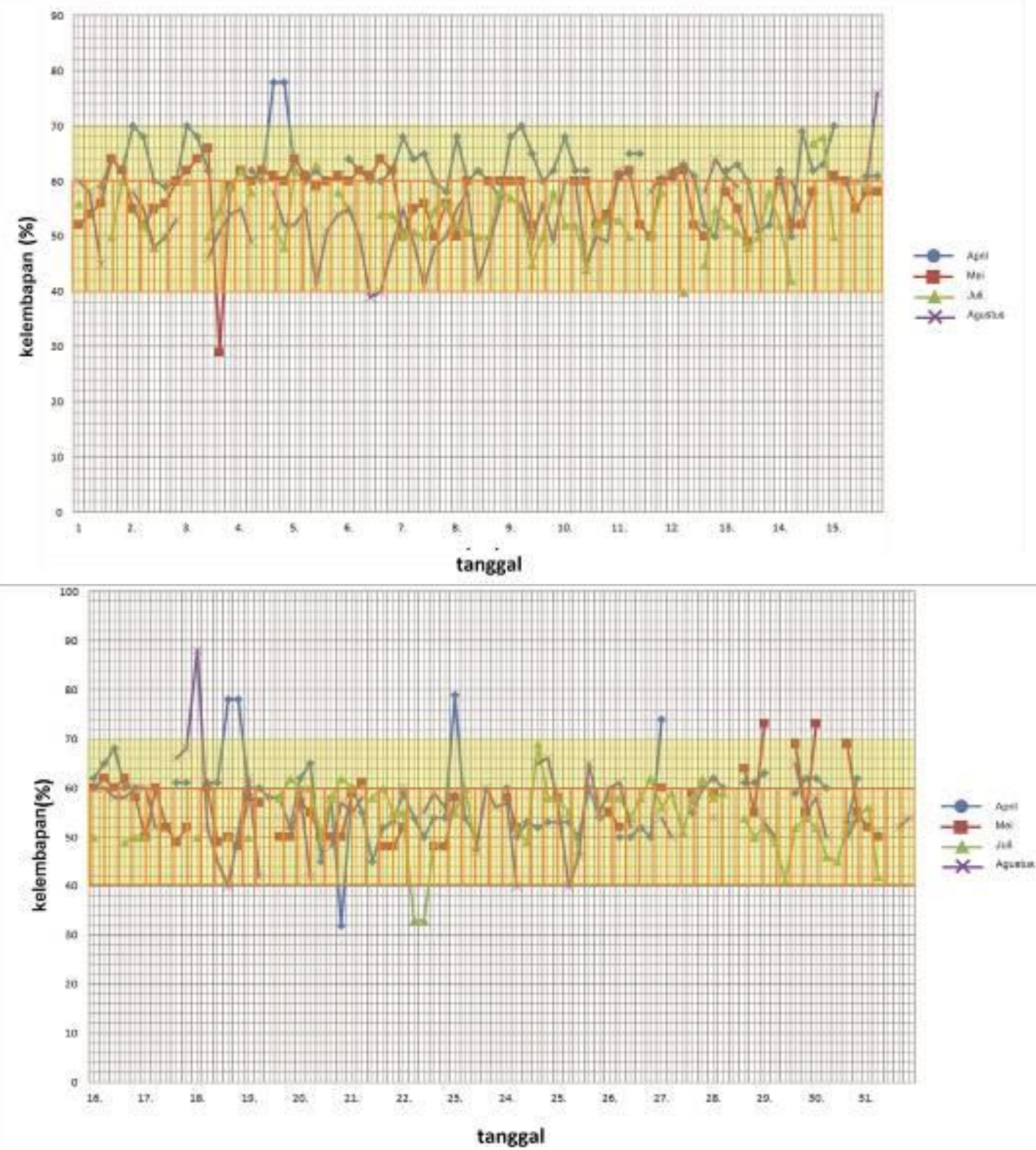

Gambar 2. Kelembapan ruang pengolahan

Ket :

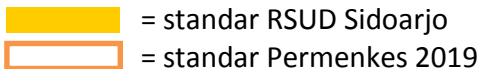

Standar kelembapan RSUD Sidoarjo lebih tinggi dibandingkan dengan standar Permenkes. Banyak data kelembapan ruang pengolahan yang apabila menggunakan standar RSUD dalam kategori aman, tetapi tidak apabila menggunakan standar Permenkes seperti ditunjukkan dalam Gambar 2. Ruang distribusi merupakan ruang transit makanan sebelum makanan yang telah diolah sampai ke pasien. Pengawasan suhu dan kelembapan diperlukan untuk menjaga kualitas makanan. Berdasarkan Gambar 3, suhu ruang distribusi terlalu tinggi untuk standar RSUD Sidoarjo. Akan tetapi dengan standar Permenkes masih tergolong suhu yang aman. 


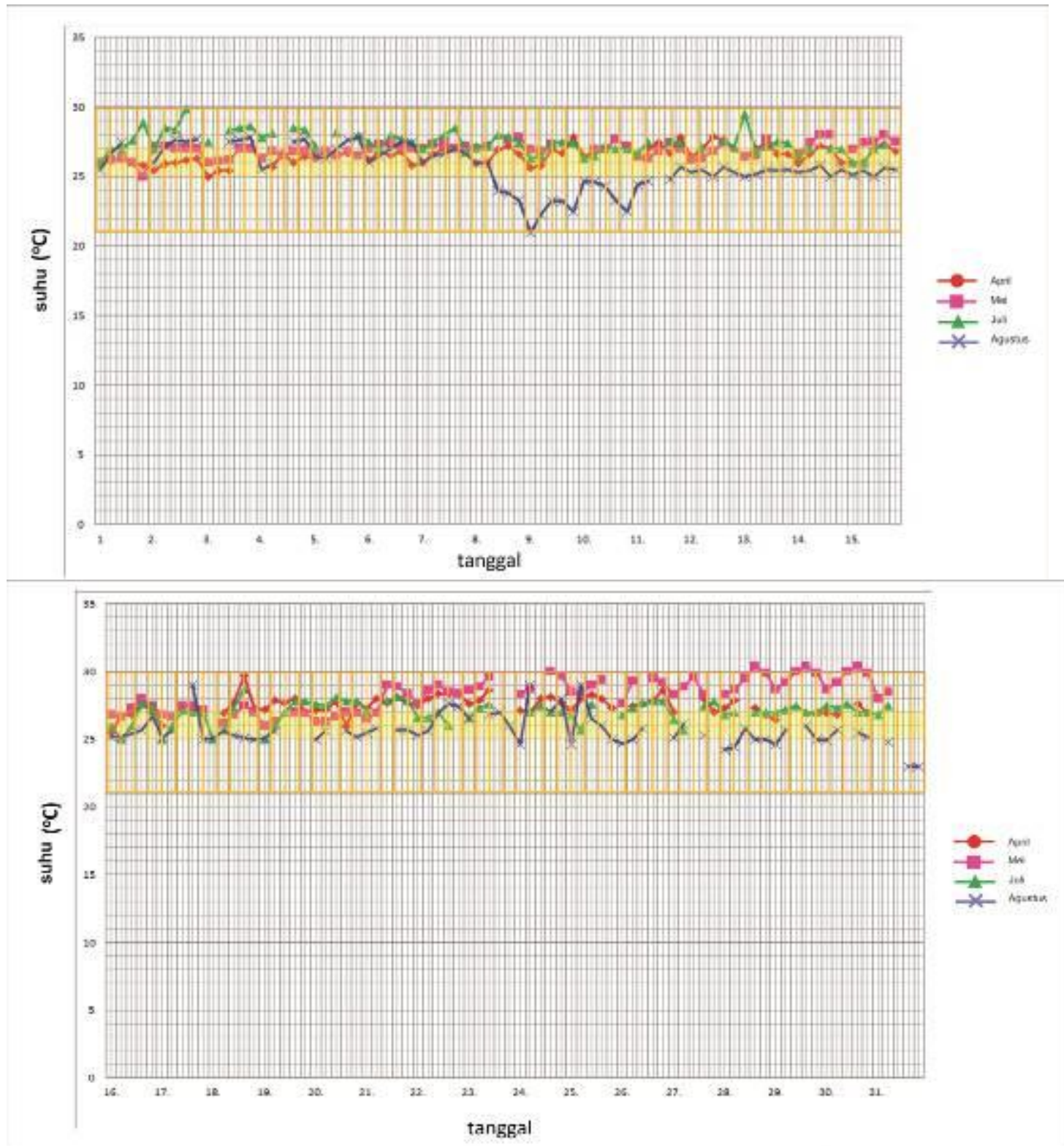

Gambar 3. Suhu ruang distribusi

Ket :

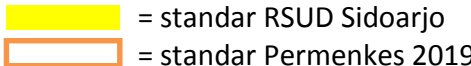

Tinggi rendahnya suhu dalam ruang pengolahan dan distribusi dapat bergantung pada intensitas matahari, dimana pada siang hari suhu dalam ruangan dapat lebih tinggi dibandingkan dengan suhu pada pagi atau sore hari. Kelembapan udara dalam suatu ruang dipengaruhi oleh suhu dalam ruangan itu sendiri. ${ }^{18}$ Semakin tinggi suhu dalam ruangan tersebut, maka kelembapan udaranya akan semakin rendah karena aktivitas air dalam ruangan tersebut sedikit. Intesitas cahaya dalam suatu ruangan juga turut mempengaruhi kelembapan udara dalam ruangan. Jika intensitas cahaya yang masuk dalam suatu ruangan tinggi, maka kelembapan udara dalam ruangan tersebut akan rendah, begitu pula sebaliknya. ${ }^{19}$

Makanan matang rentan terhadap pertumbuhan bakteri. Apabila ruang distribusi memiliki kelembapan yang terlalu tinggi dapat meningkatkan risiko masalah keamanan pangan. Kelembapan di ruang distribusi RSUD Sidoarjo sangat tinggi dari standar kelembapan RSUD Sidoarjo maupun standar Permenkes. Oleh karena itu diperlukan evaluasi mengenai kelembapan di ruang distribusi untuk mempertahankan kualitas makanan dan kenyamanan pegawai. Penelitian Reglier-Poupet (2005) di Necker Enfants Malades Hospital menunjukkan suhu dan kelembapan dapur dapat berpengaruh pada pertumbuhan mikrobia terutama pada makanan segar seperti salad (10\% jumlah keseluruhan piring memiliki total viable counts bakteri diatas standar atas) ketika disajikan ke pasien. ${ }^{19}$

Kelembapan yang tinggi perlu diwaspadai karena dapat menumbuhkan bakteri lebih cepat. Kelembapan 
berkaitan dengan kadar air di suatu ruangan. Apabila kelembapan ruangan di atas $60 \%$ dapat menyebabkan berkembangnya mikroorganisme patogen maupun alergen. Kelembapan udara berhubungan aktivitas air, semakin tinggi kelembapan udara maka akan semakin tinggi aktivitas air di sekitar ruangan. ${ }^{20}$ Tingginya aktivitas air di dalam ruang pengolahan dan distribusi akan memicu kerusakan makanan karena akan memicu aktivitas mikroorganisme pada makanan. ${ }^{21}$ Kelembapan yang tinggi di ruang distribusi dapat disebabkan oleh kurangnya ventilasi di ruangan tersebut. Luas ventilasi minimal $15 \%$ dari luas ruangan. Berdasarkan hasil observasi, luas ruangan di ruang distribusi Instalasi Gizi RSUD Sidoarjo sekitar $85,5 \mathrm{~m}^{2}$, sehingga ventilasi yang ada setidaknya seluas $12,8 \mathrm{~m}^{2}$. Akan tetapi, ternyata ventilasi di ruang distribusi hanya $1 \mathrm{~m}^{2}$ dan hanya memenuhi $1,2 \%$. Sebenarnya di ruang distribusi memiliki kaca transparan yang cukup luas, akan tetapi hanya dikhususkan untuk pramusaji yang mengambil makanan untuk diletakkan ke dalam troli. Hal tersebut juga untuk menjaga kualitas makanan agar tidak tercemar oleh cemaran dari luar. Oleh karena itu, diperlukan evaluasi kembali mengenai sistem ventilasi di ruang distribusi agar kelembapan ruangan dapat terjaga dan makanan pun tidak mengalami cemaran. ${ }^{16}$

Data kelembapan ruang distribusi lebih tinggi jika dibandingkan dengan kelembapan ruang pengolahan. Hal ini juga berkaitan dengan suhu ruangan. Suhu ruang produksi lebih tinggi dibandingkan ruang distribusi. Suhu yang tinggi dapat meningkatkan penguapan air sehingga kadar air semakin rendah dan kelembapan ruangan pun rendah, begitupun sebaliknya. ${ }^{20}$ Penelitian Azizpour (2013) menunjukkan pekerja di dapur University Kebangsaan Malaysia Medical Center merasakan suhu kerja di dapur setinggi $27,25^{\circ} \mathrm{C}$ terasa hangat dan berada diatas suhu nyaman untuk efektif bekerja yakni pada $25^{\circ} \mathrm{C}{ }^{24}$

Dapur dengan kelembapan dan suhu yang tinggi dapat menyebabkan pekerjanya merasakan heat stress. Hal ini dapat menyebabkan terjadinya acute heat stroke, masalah sirkulasi darah, dan ketidak nyamanan dalam bekerja. Apabila heat stress terjadi bersamaan dengan dehidrasi, maka dapat menyebabkan gagal ginjal akut atau kronis karena deplesi air dan natrium sebagai akibat tingginya mikroalbuminuria. ${ }^{25}$ Penelitian Kim (2016) menunjukkan suhu dalam ruang dan ventilasi yang buruk pada area dapur rumah sakit menjadi masalah tersering (32\%) dalam penyelenggaraan makanan rumah sakit diatas permasalahan ukuran dapur yang kecil, kurangnya tenaga kerja, dan kurangnya kontrol kesehatan kerja. Hal ini menyebabkan resiko jatuh, terbakar, terpotong, dan terbentur yang lebih besar karena hilangnya konsentrasi pekerja. ${ }^{26}$ Temperatur tinggi dalam dapur dapat menyebabkan rasa tidak nyaman pada pekerja yang mengarah pada productivity loss hingga $30 \%$. Menurunkan suhu di dapur hingga level nyaman dapat meningkatkan $30 \%$ produktivitas. ${ }^{27}$

Dalam penelitian ini dapat diketahui fluktuasi data suhu dan kelembapan udara di dalam ruang pengolahan dan ruang distribusi Instalasi Gizi RSUD Kabupaten Sidoarjo. Namun dalam penelitian ini belum dilakukan penelitian langsung pengaruh perubahan suhu dan kelembapan udara tersebut terhadap makanan yang dihasilkan dan produktivitas kerja pekerja. Analisis data dalam penelitian ini dapat digunakan sebagai dasar rekomendasi evaluasi aliran udara berkelanjutan dalam ruangan untuk menjaga suhu dan kelembapan sesuai dengan standar Permenkes no 7 Tahun 2019.

\section{KESIMPULAN}

Gambaran Suhu dan kelembapan udara di ruangan pengolahan dan distribusi di Instalasi Gizi RSUD Kabupaten Sidoarjo dapat disimpulkan terdapat data yang cukup fluktuatif. Secara umum, suhu dan kelembapan udara di ruang pengolahan dan distribusi sudah memenuhi standar yang ditetapkan oleh Kementerian Kesehatan dalam Permenkes no 7 Tahun 2019. Bagi instalasi gizi diharapkan dapat melakukan evaluasi kepuasan pasien serta standar suhu dan kelembapan di ruang distribusi dan suang pengolahan RSUD Sidoarjo secara rutin dan menyeluruh agar mengetahui penyebab lain terjadinya tinggi rendahnya suhu maupun tinggi rendahnya tingkat kelembapan ruang distribusi dan ruang pengolahan, sehingga nantinya mampu meningkatkan daya terima pasien terhadap makanan yang disajikan.

\section{ACKNOWLEDGEMENT}

Penulis berterimakasih kepada RSUD Kabupaten Sidoarjo atas izin untuk melakukan pengambilan data. Penulis berterimakasih kepada kepala instalasi gizi, ahli gizi, pramusaji dan seluruh staff di Instalasi Gizi RSUD Sidoarjo utamanya kepada dosen pembimbing di RSUD Sidoarjo Ismi Indah Ummi S.Gz dan kepala pramusaji RSUD Kabupaten Sidoarjo Muhammad Fahmi Nasrullah.

\section{REFERENS}

1. Hartwell, H.J., Edwarts, J.S.A. Symonds. Food Serrvice in Hospital: Development of a Theoretical Modedi Foe Patient Experience And Statification Using on Hospital in the UK National Health Service as a Case Study. Journal of Food Service. 17, 226-236 (2006).

2. Ayudhia, D. Asupan makanan, status gizi dan lama hari rawat inap pada pasien penyakit dalam di rumah sakit advent Manado. GIZIDO . 8, 22 (2016).

3. Koen F.M. \& Jessie M.H.. Prevalence of malnutrition in pediatric hospital patients. Journals Iww. 5, 590-596 (2008)

4. Atmanegara, Wa Ode., Djunaidi M.D., \& Yustini. Gambaran tingkat kepuasan siswa terhadap mutu hidangan pada penyelenggaraan makanan di sekolah polisi negara (SPN) Batua Polda Sulsel tahun 2013. Jurnal Universitas Hasanuddin (2013)

5. Widyastuti, N. \& Pramono, A. Manajemen jasa boga. (Graha Ilmu, 2014).

6. Depkes RI. Pedoman Pelayanan Gizi Rumah Sakit. 
Sari, dkk. Amerta Nutr (2021). 68-74

DOI: 10.2473/amnt.v5i1.2021. 68-74

(2013). Tersedia di: https://www.persagibandung.org/2017/12/ped oman-pgrs-pelayanan-gizi-rumah-sakit.html

7. Menteri Kesehatan Republik Indonesia. Peraturan Menteri Kesehatan Republik Indonesia Nomor 1096/MENKES/PER/VI Tahun 2011 tentang Persyaratan Higiene Sanitasi Jasaboga. (2011). Tersedia di http://kesmas.kemkes.go.id/perpu/konten/per menkes/pmk-nomor-1096-tahun-2011-tentanghigiene-sanitasi-jasaboga

8. Septiani Chaerina Putri, Wulandari AR. Gambaran Higiene Sanitasi Makanan dan Penerapan Prinsip Hazard Analysis Critical Control Point ( HACCP ) di Unit Instalasi Gizi Rumah Sakit X Tahun 2018 Abstrak. 1, 55-64 (2020).

9. Di M, Sunankalijaga R, Demaktahun K, Sonia V, Koesyanto H, W AS. Evaluasi Penerapan Higiene Dan Sanitasi penyelenggaraan Makanan Di Rsud Sunankalijaga Kabupaten Demaktahun 2013. Unnes J Public Heal. 4, 124-131 (2015).

10. Yulia. Higiene Sanitasi Makanan, Minuman dan Sarana Sanitasi terhadap Angka Kuman Peralatan Makan dan Minum pada Kantin. J Vokasi Kesehat. 1, 55-61 (2016).

11. Yulianto, A. N. Food \& BeveragePenerapan Standard Hygiene dan Sanitasi dalam Meningkatkan Kualitas Makanan di Food \& Beverage Departement @Hom Platinum Hotel Yogyakarta. J Khasanah Ilmu. 2, 31-39 (2015).

12. Abdullah MT, Hakim BA. Lingkungan Fisik dan Angka Kuman Udara Ruangan di Rumah Sakit Umum Haji Makassar, Sulawesi Selatan. Kesmas Natl Public Heal J. 5, 206 (2011).

13. Sarinda A, Sudarti, Subiki. Analisis Perubahan Suhu Ruangan Terhadap Kenyamanan Termal di Gedung 3 Fkip Universitas Jember. J Pembelajaran Fis. 3, 305- 311 (2017).

14. Wardhani sri muri dasa. Pengaruh Suhu dan Waktu Penyimpanan terhadap Pertumbuhan Bakteri Staphylococcus Aureus pada Makanan Sosis Siap Santap Di Medan. (2016).

15. Menteri Kesehatan Republik Indonesia. Peraturan Menteri Kesehatan Republik Indonesia Nomor 7 Tahun 2019 tentang Kesehatan Lingkungan Rumah sakit. (2019). Tersedia di: https://peraturan.bpk.go.id/Home/Details/1117 21/permenkes-no-7-tahun-2019

16. Suhendar, Ervan Efendi H. Audit Sistem Pencahayaan dan Sistem Pendingin Ruangan di Gedung Rumah Sakit Umum Daerah ( RSUD )
Cilegon. Setrum. 2, 21-27 (2013)

17. Shehadi M. Review of Humidity Control Technologies in Buildings. Journal of Building Engineering. 19, 539-551 (2018).

18. Haditia. Analisis Pengaruh Suhu Tinggi Lingkungan dan Beban Kerja Terhadap Konsentrasi Pekerja. Universitas Indonesia (2012).

19. 17. Shehadi M. Review of Humidity Control Technologies in Buildings. Journal of Building Engineering. 19, 539-551 (2018). 20. Purnama, Ansar SHA. Keterkaitan Suhu Dan Kelembaban Udara Ruang Penyimpanan Terhadap Kadar Air Jagung Pada Bangunan Penyimpanan ( Studi Kasus Pada Gudang K . U . D . Di Desa Pringgasela Kecamatan Pringgasela ). 113 (2013).

21. Fachruri M, Muhidong J, Sapsal MT. Analisis Pengaruh Suhu dan Kelembaban Ruang terhadap Kadar Air Benih Padi di Gudang Penyimpanan PT. Sang Hyang Seri. J Agritechno. 2, 131-137 (2019).

22. Rahardjo B, Bintoro N, Hastuti P. Pemodelan Matematik Perubahan Parameter Mutu Selama Penyimpanan Dan Sorpsi-Isotermi Kerupuk Goreng Pasir. 3, 265-274 (2013).

23. Ayu A. A., Daryatmo J. Perubahan Kelembaban dan Kadar Air Teh Selama Penyimpanan pada Suhu dan Kemasan yang Berbeda. J Apl Teknol Pangan. 4, 124-129 (2015).

24. Azizpour F., Moghimi S., Salleh E., Mat S., Lim C.H., Sopian K. Thermal Comfort Assessment of Large Scale Hospitals in Tropical Climates: A Case Study of University Kebangsaan Malaysia Medical Centre (UKMMC). Energy and Buildings. 64, 317-322 (2013).

25. Singh A., Kamal R., Mudiam M.K.R., Gupta M.K., Satyanarayana G.N.V., Bihari V. Heat and PAHs Emissions in Indoor Kitchen Air and Its Impact on Kidney Dysfunctions among Kitchen Workers in Lucknow, North India. PLoS ONE 11(2): e0148641 (2016). doi:10.1371/journal.pone.014864

26. Menteri Kesehatan Republik Indonesia. Peraturan Menteri Kesehatan Republik Indonesia Nomor 7 Tahun 2019 Kim H.J., Hong J.I., Heo G.J., Park J.Y. Case Study on Safety Situation and Awareness Through Risk Assessment on Hospital Foodservice Kitchen Area. J Korean Diet Assoc. 22(1), 13-25 (2016)

27. Suhendar, Ervan Efendi H. Audit Sistem Pencahayaan dan Sistem Pendingin Ruangan di Gedung Rumah Sakit Umum Daerah ( RSUD ) Cilegon. Setrum. 2, 21-27 (2013) . 